\title{
Work transition tip: Work Seeking and Retention Issues: Strategies for Persons with Vision Loss
}

This kit tip sheet developed by Chelsea Mohler, Lynn Shaw, and Lisa Klinger in 2013

Was Reviewed by: Warren Northcott and Jennifer Millard from the Canadian National Institute for the Blind (CNIB) 2013
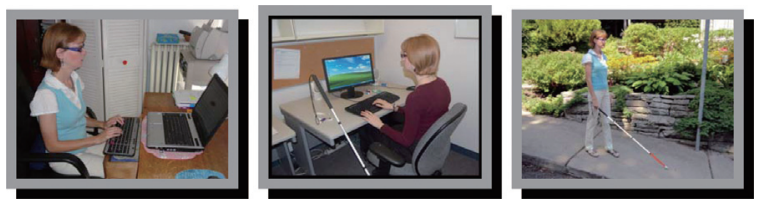

"Frankly, this job was not my first choice... But, the [employer] and my clinic accommodates me and understands my needs. So I do a job I don't like as much but don't have to fight for accommodation."

National estimates in Canada indicate that only $32 \%$ of persons with vision loss are employed and many of those that do work are underemployed [1] Part of the difficulty with finding and retaining work, as well as the need to settle 'for second best' in order to become employed, relates to the lack of suitable technology within workplaces, a lack of knowledge of how to interact with employees with vision loss, and a belief that employees with vision loss are potentially more costly, less productive, and more troublesome [2]. Lack of access to the knowledge and support needed to facilitate ongoing needs of workers with vision loss often also results in persons with vision loss being let go as work tasks or processes change. For employers, this lack of know-how continues to be the main barrier to hiring and retaining persons with vision loss and for persons with vision loss it often leads to a cycle of short-term employment followed by long periods of unemployment [3].

There are several important consequences to the current situation. Employers lose out on the opportunity to hire potentially effective, loyal, and productive workers, even as the quality and availability of adaptive technology is improving and its cost is decreasing. The pattern of chronic or intermittent unemployment of persons with low vision also perpetuates a reliance on public support and reinforces public policies that discourage seeking and accepting employment. For example, those who work part-time or contractually while on social assistance receive a claw back on not only their income support but to their medical benefits; this forces individuals to choose between seeking gainful work and maintaining health coverage [3]. Additionally, education on what coverage is available to participants working while receiving social assistance can be inaccessible to locate, as many of the forms and documents related to social assistance are not available in a format a person with vision loss can read [3]. As a result there is greater public economic burden as a consequence of persons remaining on social assistance when they could be employed [4].

One way to address the hiring and retention dilemma is to provide access to employment counselors and job coaches, who can play a role in assisting both those with vision loss and employers. Counselors can assist persons with vision loss in finding employment opportunities, determining the optimal timing for disclosure, and developing strategies for overcoming barriers involved in getting to and from work and in carrying out work-related duties. Counselors can also gain expertise by collaborating with employers who have been suc- 
cessful in hiring individuals with vision loss and then, as they become more knowledgeable, educate potential employers. Job coaches can be useful in helping persons with vision loss and their employers develop specific day-to-day strategies for dealing with on-the-job challenges.

Research [1,3] indicates that persons with vision loss experience:

- multiple barriers in the hiring process and in retaining meaningful work

- inaccessible job application forms

- disadvantages in hiring processes requiring them to disclose disability in the application process i.e., job ads available only on paper

- job performance stigmatization from employers

- support inequities and disincentives to becoming employed

- technologies in work places that are incompatible with assistive technologies for low vision

- underemployment - they have more skills than the job requires

- restrictions in employment opportunities to jobs that are accessible only by public transit

Research [3,5-7] indicates that persons with vision loss address some of these employment challenges by:

- Working with employment support agencies to locate job ads and complete applications

- Not disclosing vision restrictions until the interview

- Providing employers with information on accommodation resources and supports

- Arranging private transit to work from friends or family

- Developing mobility and navigational skills

Employment Counselors [2,3,6,7] can support work retention by:

- Developing expertise in the following competencies: partnering and networking skills, technology skills in using assistive technology and in developing accessibility, work-vision demands analysis, coaching for disclosure for persons with vision loss, and employers, accommodation and accessibility plans for workplaces.

- Working with employers to set up "trial" periods of employment

- Connecting employees with volunteer readers in the hiring process such as reading job ads

- Educating companies on how to create accessible job notices on the part of employment agencies
- Working with employers to develop vision accessibility guidelines in hiring

- Advocating for stronger legislation to support inclusion and accessibility to employment

- Educating employers on accessing low cost technologies to support employment

- Providing ongoing partnering and support for vision-restricted employees

- Working with employers to develop an accommodation plan that includes statements on accommodation in job ads - such as : accommodations available upon request

- Educating employers on how to make the workplace accessible beyond the "physical work environment" (Example: inclusive workplace policies)

Persons with vision loss $[1,3]$ can:

- Develop effective self-advocacy skills regarding timing of disclosure and strategies for meeting accommodation needs

- Develop community mobility skills

- Partner with community organizations or individuals willing to provide support

- Develop knowledge and skills in using assistive technology that meets their needs

- Get involved at a community level with organizations or groups that advocate for persons with low vision

- Be knowledgeable about legislation that protects their rights

For further information please contact leshaw @uwo. ca for further information.

\section{References}

[1] Shaw A, \& Gold D. Identifying the Facilitators of Successful Employment for Persons with Vision Loss. Toronto: CNIB; 2007. Available from http://www.cnib.ca.

[2] Crudden A, Sansing W, \& Butler S. Overcoming Barriers to Employment: Strategies of Rehabilitation Providers. Journal of Visual Impairment \& Blindness, 2005; 99: 325-335.

[3] Mohler C. The Process of Obtaining and Retaining Employment amongst the Vision-Restricted: A Constructivist Grounded Theory Study. London: Western University Unpublished (2012) Masters Thesis Available from http://ir.lib.uwo. $\mathrm{ca}$ /digitizedtheses/.

[4] Ministry of Community and Social Services [home page on the internet]. Ontario; 2011. About Social Assistance in Ontario. Retrieved from www.mcss.gov.on.ca/en/mcss/programs/ social/index.aspx.

[5] Leonard R, D'Allura T, \& Horowitz, A. Factors associated with employment among persons who have a vision impairment: A Follow-up of vocational placement referrals. Journal of Vocational Rehabilitation, 1999; 21:33-34. 
[6] Wan DWan D. Training and employment of people with disabilities. Hong Kong SAR, 2002. Available from digitalcommons.ilr.cornell.edu.
[7] O'Day, B. Employment Barriers for People with Visual Impairments. Journal of Visual Impairment and Blindness, 1999, 93: 627-642. 